\title{
The Neural Underpinnings of Group Life
}

\author{
Deborah A. Prentice \\ Princeton University \\ Jennifer L. Eberhardt \\ Stanford University
}

Social psychology has always been opportunistic when it comes to method, eagerly availing itself of new methodologies developed in other fields. In the study of group processes and intergroup relations, these methodological shifts have initiated periods of unusual productivity and growth. For example, systematic observational methods, first developed in medicine, provided the basis for the foundational work in group dynamics conducted in the 1930s, 1940s and 1950s. Experimental methods, pioneered in the field of perception and psychophysics, led to seminal research by Sherif (1936) on group influence and Lewin, Lippitt, and White (1939) on group dynamics and leadership (Jones, 1998). More recently, methods developed in cognitive psychology, especially those using computerbased paradigms and reaction-time measures, have led to impressive advances in the study of intergroup relations (Fazio \& Olson, 2003).

The newest opportunity on the methodological horizon comes from developments in neuroscience. Recent advances in functional neuroimaging techniques, for example, have enabled researchers to measure indirectly neural activity in awake and behaving humans. Thus, the question of what neural events mediate between stimulus and response has suddenly become much more tractable. Not surprisingly, psychologists have rushed to embrace these new methodologies, which promise a deeper and more fine-grained understanding of the mental processes that define human experience. Social psychologists, including those interested in groups, have been no exception. The result of their efforts is the burgeoning field of social neuroscience.

This Special Issue offers a diverse set of theoretical and empirical articles that highlight recent advances in this field. These contributions address time-honored questions about intragroup and intergroup processes: How do perceptions of ingroup and outgroup members differ? How do people perceive status cues? When are outgroup members threatening? How does perspective-taking work? What does it feel like to be stigmatized? How do women and men differ in emotional responding? Extensive literatures exist on all of these topics. What the present contributions add to this earlier work is a different kind of answer to these timehonored questions, one that treats the underlying intrapsychic processes with great depth and precision.

\footnotetext{
$\overline{\text { Author's note }}$

Address correspondence to

Deborah A. Prentice, Department of Psychology, Princeton University, Green Hall, Princeton, NJ 08544-1010, USA

[email: predebb@princeton.edu]
} 
Indeed, their high degree of precision about psychological process accounts for much of the scientific appeal of neuroscience methods. Consider, for example, the question of whether women and men differ in emotional responding. The behavioral evidence is equivocal on this question, even if one distinguishes behaviorally between emotional reactivity and emotion regulation. However, at a neural level, gender differences emerge, reflecting differences in how women and men regulate negative affect (McRae, Ochsner, Mauss, Gabrieli, and Gross, this issue). Men, it appears, may use conscious control to suppress negative affect, whereas women may generate positive affect to offset the negative. This ability to distinguish a reduction in negative affect from an increase in positive affect-that is, to parse psychological processes this finely-is characteristic of research using neuroscience methods. With these methods, researchers can isolate specific processes and distinguish them from their close cousins. They can distinguish perceptions of threat from perceptions of dominance (Chiao et al. this issue), for example, or misregulation from underregulation (Derks, Inzlicht, and Kang, this issue).

Another dimension on which measures of neural activity offer increased precision over behavioral methods is timing. Processing of a social stimulus does not occur in an instant; rather, it unfolds over time, with attention shifting to different aspects of the stimulus at different stages of processing. For example, studies of the role of race in face processing have shown that people first attend to whether the face is the same race or a different race than their own, then to the familiarity of the face, and then to whether the face is the same race or a different race than the one that preceded it (WilladsenJensen and Ito, this issue). These shifts of attention occur extremely rapidly, all within approximately $500 \mathrm{~ms}$. Thus, measures that require a behavioral response are too crude to pick them up. However, event-related potentials (ERPs), recorded continuously as a participant views the stimulus, can provide data on neural responses that reflect those shifts in attention. With these data, researchers can draw inferences about how important group membership is in person perception-how much attention it receives and how early it receives that attention. Note that not all neural measurement techniques can provide these data. For example, functional magnetic resonance imaging (fMRI) provides very good information on spatial patterns of neural activity, but very poor information on the timing of that activity. ERPs, on the other hand, provide just the reverse: good time resolution but poor spatial resolution. Thus, ERPs are the method of choice for examining temporal patterns in attention to social category and status information (Chiao et al., this issue; Willadsen-Jensen \& Ito, this issue).

A third feature that contributes to the appeal of neuroscience methods is the range of processes they measure in parallel. Consider, for example, a recent study by Krendl, Richeson, Kelley, and Heatherton (2008) on the neural processes underlying stereotype threat. In this study, women were induced to experience stereotype threat regarding their math performance while fMRI measured their brain activity. Compared with women who were not induced to experience stereotype threat, the threatened women showed less recruitment of neural regions associated with math learning and performance and more recruitment of regions associated with emotion regulation and the processing of social feedback. Thus, the performance decrement associated with stereotype threat appears to result from two separate processes, one cognitive and the other emotional, working in concert. To reach this conclusion, the researchers had to be able to measure both of these processes simultaneously and implicitly. Of the methods available today, only fMRI has this capacity. Indeed, neuroimaging has enabled researchers to chart the interplay of cognitive and affective processes in a variety of domains (see Derks, Inzlicht, and Kang, this issue; McRae et al., this issue; Richeson, Todd, Trawalter, and Baird, this issue).

A final appeal of neuroscience methods is that they facilitate integration of social psychological findings with related research on 
diverse populations, including children, clinical patients, and nonhuman primates. Until recently, such integration has been difficult to accomplish. Researchers have analyzed behavioral patterns across human populations and species, but these analyses have afforded only limited insight into psychological process. Studies of process, on the other hand, have used measures that have limited utility beyond high-functioning, adult populations (e.g., self-reports, reaction times). One of the promises of social neuroscience, for the study of groups in particular, is an integrated view of the psychological processes that underlie collective living. Indeed, diverse populations provide valuable perspectives on the evolved biological systems that neuroscience methods measure. Thus, once social psychologists adopt this level of analysis, comparative, developmental, and clinical psychology become potential sources of valuable insight. This insight is already evident in the study of perspective-taking (Mason and Macrae, this issue), perceptions of dominance (Chiao et al., this issue), and intergroup threat (Richeson et al., this issue).

We have focused on the ways in which neuroscience methods promise to enhance the study of group processes and intergroup relations. Despite this promise, however, social psychologists are not united in their enthusiasm for the wide-spread adoption of these methods. There are many, very legitimate reasons for concern (see Dovidio, Pearson, and Orr, this issue), one of which, we believe, drives much of the anxiety. The fact is that neural measures are limited in what they can reveal about group life-limited in the questions they can be used to address and in the answers they can provide to those questions. In this respect, neural measures are no different from any other single, methodological approach to studying social psychological processes. But as the field embraces neuroscience methods, as funding agencies preferentially allocate funds for this kind of research, and as neural evidence for psychological process becomes more common, many researchers are coming to fear that these methods will define the field-that is, that neural evidence for process will become the accepted standard of good research. There is no question that this would be a negative outcome. If the field of group processes and intergroup relations came to be defined by the questions that neuroscience methods can address, it would be a far less interesting, generative, and creative field than it is today. That said, it would be a shame not to exploit the enormous power and potential of these new methods. Even acknowledging their limitations, it is clear that they have a great deal to contribute to the study of group life.

With these brief introductory remarks, we turn the task of further exploration over to the contributors. They have produced a set of articles, each of which offers its own take on how neural measures data advance our understanding of intragroup and intergroup processes. Taken together, these articles illustrate the versatility of neuroscience methods, the level of analysis they adopt, and how they can be used, in combination with behavioral and cognitive methods, to provide new insight into the psychology of group life. We hope that readers of this Special Issue come away educated about what neuroscience has to offer and perhaps thinking a little differently about their own research agendas.

\section{References}

Fazio, R. H., \& Olson, M. A. (2003). Implicit measures in social cognition research: Their meaning and use. Annual Review of Psychology, 54, 297-327.

Jones, E. E. (1998). Major developments in five decades of social psychology. In D. T. Gilbert, S. T. Fiske, \& G. Lindzey (Eds.), The handbook of social psychology (Vol. 1, pp. 3-57). New York: McGraw-Hill.

Krendl, A. C, Richeson, J. A., Kelley, W. M., \& Heatherton, T. F. (2008). The negative consequences of threat: An fMRI investigation of the neural mechanisms underlying women's underperformance in math. Psychological Science, 19, 168-175.

Lewin, K., Lippitt, R., \& White, R. K. (1939). Patterns of aggressive behavior in experimentally created 'social climates'. Journal of Social Psychology, 10, 271-299.

Sherif, M. (1936). The psychology of social norms. New York: Harper. 


\section{Biographical notes}

DEBORAH A. PRENTICE is professor of psychology and chair of the psychology department at Princeton University. She received her PhD in psychology from Yale University. Her research interests include social influence, psychological essentialism, and social dilemmas.
JENNIFER L. EBERHARDT is an associate professor of psychology at Stanford University. She received her $\mathrm{PhD}$ in psychology from Harvard

University. Her research interests include racial categorization, stereotyping, and discrimination. 